\title{
Role of Mifepristone in treatment of uterine fibroid: an experience from tertiary care centre in South India
}

\author{
S. V. Nachiketha, Veena Hadi* \\ Department of Obstetrics and Gynecology, KIMS, Hubli, Karnataka, India \\ Received: 10 January 2019 \\ Accepted: 05 February 2019 \\ *Correspondence: \\ Dr. Veena Hadi, \\ E-mail: veenahadi@gmail.com \\ Copyright: (C) the author(s), publisher and licensee Medip Academy. This is an open-access article distributed under \\ the terms of the Creative Commons Attribution Non-Commercial License, which permits unrestricted non-commercial \\ use, distribution, and reproduction in any medium, provided the original work is properly cited.
}

\begin{abstract}
Background: Uterine fibroid are the most common benign tumour of the uterus and is seen in $20 \%$ of women in their reproductive age group. The aim of the study was to evaluate effect of Mifepristone on uterine fibroid with reference to reduction in size of fibroid and change in symptomatic profile.

Methods: It is a hospital based interventional study conducted at KIMS Hubli hospital. 98 patients with symptomatic fibroid uterus were given 50mg of Mifepristone on alternate day for 3 months.

Results: Mifepristone treatment significantly reduced mean PBAC score from baseline score of 212.61 to 20.39 at the end of 3rd month of therapy. Mean fibroid volume also reduced significantly from baseline value of $237.95 \mathrm{~cm} 3$ to $30.45 \mathrm{~cm} 3$ after 3 months of treatment. At the end of therapy hemoglobin was raised from $9.57 \mathrm{~g} / \mathrm{dl}$ at baseline to $10.42 \mathrm{~g} / \mathrm{dl}$ after 3 months of treatment. No major side effects were observed, and $7 \%$ patients had hysterectomy.

Conclusions: Mifepristone is very useful option in perimenopausal women with symptomatic fibroid. It reduces fibroid size and its symptoms without any major side effects. However, future long term RCTs are needed to assess the safety and efficacy of Mifepristone.
\end{abstract}

Keywords: Fibroid uterus, Mifepristone, PBAC scores, VAS score

\section{INTRODUCTION}

Leiomyoms of the uterus, uterine fibroids or myomas, are the most common benign tumour found in women in their reproductive age group. Epidemiological studies indicate that up to 74 percent of pre-menopausal women will have evidence of uterine fibroids on histological examination. ${ }^{1}$ The fibroid prevalence increases with age, until the age of menopause and increase in the average age of conception recently thought to be contributing factor and fibroids are increasingly resulting in the fertility problems. ${ }^{2,3}$ Risk factors for uterine fibroid includes early menarche, delayed pregnancy, obesity, race, age, genetic alterations, caffeine and a diet rich in red meat. Most of the time initial diagnosis is made by general practitioners in the community depending upon the patient history and examination. On palpation of abdomen firm, mobile, nontender mass is felt if fibroid is of large size. 2dimensional (2D) ultrasound (USG) is used for confirmation of diagnosis. The symptoms caused by fibroids vary significantly. Even though myomas are very common, significant symptoms are seen in only around half of women that require medical intervention. Improving the quality of life with fulfilling the individual woman's expectations is the primary aim of fibroid management. Treatment modality will be dictated by future fertility expectations of women and severity of symptoms. For symptomatic fibroid the definitive treatment always been surgical and fibroids accounts for around $40 \%$ of all hysterectomies done in premenopausal women. $^{4}$ Medical treatment is given to relieve the symptoms like heavy menstrual bleeding and pain so as 
to improve the overall quality of life. The progesterone controls the growth of fibroid and causes proliferating cell nuclear antigen (PCNA) and EGF expression and up regulation fibroid cells. ${ }^{5}$

Progesterone increases the expression of $\mathrm{Bcl}-2$ protein, which is apoptosis-inhibiting gene product of the oncogene bcl-2. Progesterone decreases the expression of tumour necrosis factor $\alpha$ (TNF $\alpha)$, this is important cytokine involved in apoptosis. There is overall decrease in apoptosis which causes continued growth of uterine fibroid. There is significant reduction in the overall mitotic activity and volume of fibroids if antiprogesterone drug i.e. Mifepristone (RU-486) is given. ${ }^{6}$ Mifepristone is a progesterone receptor modulator with primarily antagonistic properties, and it has antiglucocorticoid action also.

Mifepristone strongly binds to endometrial progesterone receptors, minimally to estrogen receptors. Mifepristone has direct effect in reducing number of progesterone receptors which contributes to the reduction in size of fibroid.

Mifepristone causes ovarian acyclicity and results in hormonal milieu similar to early follicular phase that may inhibit steroid dependent growth of fibroid. Mifepristone also causes inhibition of ovulation resulting in amenorrhea. Reduction in stromal vascular endothelial growth factor (VEGF) and direct suppressive effects on endometrial vasculature by Mifepristone have been suggested in decreasing the menstrual blood loss. ${ }^{7}$

\section{METHODS}

It is a hospital based prospective interventional study. Permission from institutional ethical committee was obtained. Patients attending the Gynecology OPD at Karnataka Institute of Medical Sciences, Hubli. Written informed consent was taken from patient for clinical examination, interventions undertaken. Relevant history was taken. A complete general and gynaecological examination was done. Blood samples were collected for checking Haemoglobin ( $\mathrm{Hb} \%)$, liver function and kidney function tests. Ultrasound (USG) was done. Patients with inclusion criteria were given, Tab Mifepristone $50 \mathrm{mg}$ alternate days for 3 months.

Patients were followed up at 1 month after starting treatment and at 3rd month. On each visit clinical symptoms assessed i.e. heavy menstrual bleeding by PBAC ((Pictorial Blood Assessment Chart) score and pain related symptoms by VAS (Visual analogue Scheme) score. Side effects experienced were also noted.

Pictorial blood loss assessment chart (PBAC) score[8], is a semi quantitative method for assessment of menstrual blood loss and it takes into account the number of pads soaked, degree of soakage, passage of clots and episodes of flooding. ${ }^{9}$
A score of 100 or more indicate menorrhagia. For pain assessment Visual analog scale (VAS) score was used. Dysmenorrhoea, abdominal pain, dyspareunia, and backache were assessed using VAS score. Patients were asked to describe their pain severity both before and after the treatment on a scale of 0 to 10 . When there is "no pain" taken at zero and for "worst possible pain" at ten.

USG was done to assess the number, type, volume of fibroids and to rule out other pelvic pathology. Volume of fibroid was calculated by Ellipsoid method and the formula $V=0.5233(\mathrm{D} 1 \times \mathrm{D} 2 \times \mathrm{D} 3)$ was used, where D1, D2 and D3 are the longitudinal, transverse and crosssectional diameters of the fibroid, respectively. In multiple fibroids each fibroid volume is added to calculate total fibroid volume. Study period was between January 2016- June 2018 with sample size of 98.

\section{Inclusion criteria}

- Women between 30-50 years of age

- Symptomatic patients of fibroid uterus

- Fibroid size less than $15 \mathrm{~cm}$ on USG.

\section{Exclusion criteria}

- Fibroids size more than $15 \mathrm{~cm}$ on USG

- Clinically fibroid is more than 20-week size of gravid uterus

- Hepatic or renal dysfunction

- Hormonal contraception or medication received (Progestogens/ Gnrh) in the last 3 months.

- Current genital infection.

\section{Statistical analysis}

The data collected was entered in Microsoft Excel and analysed using SPSS software. Statistical analysis was done using appropriate statistical methods.

\section{RESULTS}

As shown in Table 1 , most of patients $(70 \%)$ were in premenopausal age group with symptomatic fibroid. Age range of patients in present study was from 35 to 50 years. In present study $57 \%$ of patients were in age group of 41 to 45 years and $22 \%$ of patients were in age group of 36 to 40 years, $13 \%$ of patients were in the age group of 46 to 50 years.

Table 1: Showing age wise distribution of fibroid uterus cases.

\begin{tabular}{|l|c|c|}
\hline Age in years & Number & $\%$ \\
\hline $30-35$ & 7 & 7.2 \\
\hline $36-40$ & 22 & 22.4 \\
\hline $41-45$ & 56 & 57.1 \\
\hline $46-50$ & 13 & 13.2 \\
\hline Total & 98 & 100 \\
\hline
\end{tabular}


Figure 1 depicts the distribution of body mass index (BMI) in the study population. In the present study mean body mass index was $25.5 \mathrm{Kg} / \mathrm{m}^{2}$ and range was from 18 to $36 \mathrm{Kg} / \mathrm{m} 2$. Most of patients $(55 \%)$ in this study were in normal range of BMI (18-25) and $45 \%$ of patients had high BMI (>25). Obesity is associated with hyperestrogenic state contributing to myoma growth.

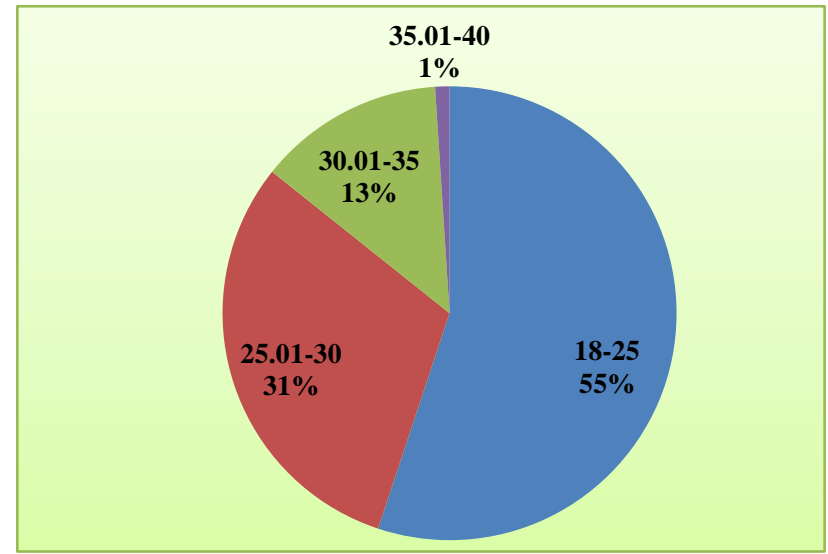

Figure 1: Distribution of patients according to body mass index $(\mathrm{BMI})\left(\mathrm{kg} / \mathrm{m}^{2}\right)$.

Figure 2 shows the distribution of symptoms with which fibroid patients presented. In the present study heavy menstrual bleeding $(84.7 \%)$ in the form of menorrhagia or polymenorrhrea was common symptom followed by pain related symptoms $(67.3 \%)$ which includes dysmenorrhea, backache and abdominal pain. Mass per abdomen was complained by only $4 \%$ patients in the present study. Most of (80\%) patients had above depicted symptoms for more than 6 months of duration.

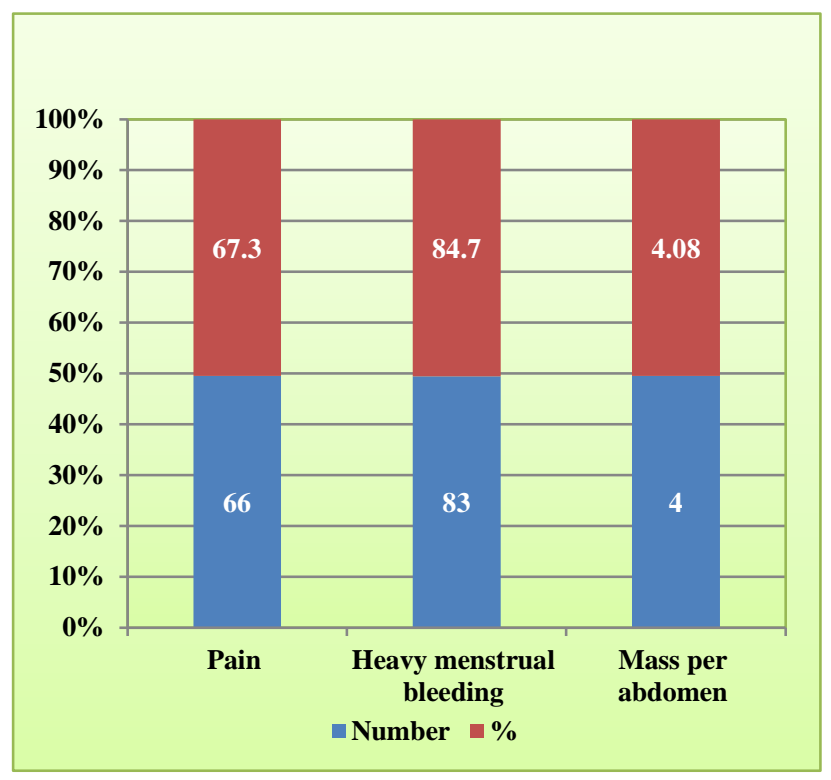

Figure 2: Distribution patient's symptoms.

Table 2: Distribution based on fibroid type.

\begin{tabular}{|l|c|l|}
\hline Pibroid type & Number & $\%$ \\
\hline Sub mucosal & 52 & 53.1 \\
\hline Intra mural & 39 & 39.8 \\
\hline Sub Serosal & 7 & 7.1 \\
\hline Total & 98 & 100 \\
\hline
\end{tabular}

Table 3: Effect of mifepristone on pictorial blood loss assessment chart (PBAC) score.

\begin{tabular}{|l|c|c|c|l|l|l|}
\hline Period & Mean & SD & Median & Minimum & Maximum & P value* \\
\hline Baseline & 212.61 & 59.99 & 239 & 68 & 286 & $<0.0001$ \\
\hline One month & 35.28 & 25.29 & 32 & 15 & 204 & $<0.0001$ \\
\hline Three months & 20.39 & 31.13 & 14 & 10 & 240 & \\
\hline
\end{tabular}

*p value by paired t test

Table 4: Effect of mifepristone on visual analog scale (VAS) score.

\begin{tabular}{|l|l|l|l|l|l|l|}
\hline Period & Mean & SD & Median & Minimum & Maximum & Palue \\
\hline Baseline & 4.92 & 3.58 & 7 & 0 & 9 & $<0.0001$ \\
\hline Three months & 2.41 & 2.02 & 3 & 0 & 7 & \\
\hline
\end{tabular}

*p value by paired $t$ test

Table 5: Effect of Mifepristone on fibroid volume.

\begin{tabular}{|l|l|l|l|l|l|l|}
\hline Period & Mean & SD & Median & Minimum & Maximum & Palue \\
\hline Baseline & 237.95 & 1856.6 & 20.12 & 1.05 & 18398 & \\
\hline Three months & 30.45 & 64.86 & 11.25 & 0 & 473.99 & $<0.0001$ \\
\hline
\end{tabular}

Table 2 depicts distribution of different types of fibroids in study population. In the present study sub mucosal fibroids (53\%) are the most common type of fibroids, as only symptomatic fibroid patients were recruited this 
study followed by intramural type (40\%) and rare variety was sub serosal type (7\%). $88 \%$ of patients had single fibroid as per ultrasound (USG) report and only $12 \%$ cases had multiple fibroids.

Table 3 shows the effect of Mifepristone in reducing blood loss which was assessed using pictorial blood loss assessment chart (PBAC) score. Baseline mean PBAC score was 212.61. At 1 month of follow up, majority of patients stopped bleeding so the mean PBAC score was reduced to 35.28 , which is statistically significant. At $3^{\text {rd }}$ month of follow up most patients continued to have amenorrhea and only few patients had per vaginal spotting and the mean PBAC score was 20.39, which again showed statistically significant reduction in mean blood loss. In the present study effect of Mifepristone in reducing pain was assessed using visual analog scale (VAS) score and it is depicted in Table 4. Baseline mean VAS score for pain related symptoms was 4.92 before starting Mifepristone therapy. At 3rd month of follow up there was statistically significant reduction in mean VAS score to 2.41 indicating improvement in patient quality of life.

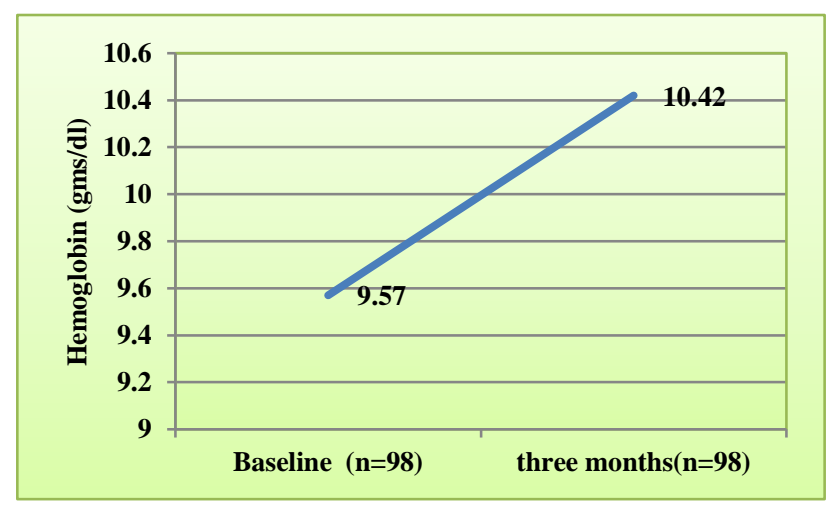

Figure 3: Effect of mifepristone on haemoglobin (Hb\%).

Figure 3 shows the effect of Mifepristone in improving the Haemoglobin level in the fibroid patients. In the present study the mean baseline Haemoglobin ( $\mathrm{Hb} \%$ ) was $9.57 \mathrm{gms} / \mathrm{dl}$ i.e. before starting treatment. After 3 months of treatment there was statistically significant rise in mean $\mathrm{Hb} \%$ to $10.42 \mathrm{gms} / \mathrm{dl}$. Mifepristone reduces the blood loss thereby improving the Haemoglobin level so more useful in anaemic patients.

Table 5 depicts the effect of Mifepristone in reducing the fibroid volume. In the present study the mean fibroid volume was $237.95 \mathrm{~cm}^{3}$ before starting treatment. And after completing 3 months of treatment mean fibroid volume was reduced to $30.45 \mathrm{~cm}^{3}$ which is statistically significant. Overall $38.7 \%$ reduction in fibroid volume is observed in this study. Majority of patients had no side effects $(n=85,86.7 \%)$. Only minor side effects were observed in few patients i.e. joint pain $(n=6,6.1 \%)$, hot flushes $(n=4,4 \%)$ and headache $(n=3,3 \%)$. At 3rd month of follow up there was raise in liver enzymes (ALT,
AST $)$ in $3 \%(n=3)$ of patients and on subsequent follow up liver enzymes returned to normal level within 4 months without any intervention.

In the present study $7 \%$ of patients underwent hysterectomy during study period, as they continued to have heavy menstrual bleeding and pain related symptoms.

\section{DISCUSSION}

Uterine fibroids are the most common benign tumours of uterus and are the most common indication for hysterectomy. As there is no single agent that could be used as definitive treatment for fibroid uterus, and wide range of options are available for management of fibroid based on the patient's clinical profile. Gonadotropin releasing hormone agonist, danazol, gestrinone, selective oestrogen receptor modulators (SERMs), aromatase inhibitors, carbegoline, antiprogestins (RU486 and asnoprisinil) are potential drugs available for treatment of fibroid uterus. Murphy et al in 1993 first reported that Mifepristone can be used in treatment of fibroid uterus. Later other studies evaluated different doses and duration of Mifepristone treatment varying from 2.5 to $50 \mathrm{mg}$ per day which was given for either 3 or 6 months of duration. Murphy et al done comparative study of $5 \mathrm{mg}, 25 \mathrm{mg}$ and $50 \mathrm{mg}$ dosage and reported that $25 \mathrm{mg}$ to be the most effective dose as it causes significant decrease in fibroid volume. Mifepristone $200 \mathrm{mg}$ strength tablet was available in our hospital and each tablet made into 4 parts ,then $1 / 4$ th tablet $(50 \mathrm{mg}$ ) was taken alternate day in the present study as $25 \mathrm{mg}$ strength tablet available in the market was costlier. ${ }^{10}$ In the present study heavy menstrual bleeding $(84.7 \%)$ and pain related symptoms $(67.3 \%)$ were main problem for women, compelling them to visit health care facilities, as it is affected their day to day activities. Similarly, in study conducted by Brig Vinod Raghav et al common presenting complaints were menorrhagia (86\%), abdominal pain (28\%), dysmenorrhoea (18\%), dyspareunia(8\%). ${ }^{11}$ In the present study baseline, 1 month and 3-month PBAC score was 212.61, 35.28, and 20.39 respectively. Comparable results are reported by Kulshrestha et al i.e. baseline, 1 month and 3 month, PBAC score of 289.2, 44.9, and 19.8 respectively in patients who were given $25 \mathrm{mg}$ of Mifepristone daily. ${ }^{7}$ And during treatment period, most $(91 \%)$ patients had amenorrhea like in all other studies. In the present study there was statistically significant improvement in haemoglobin ( $\mathrm{Hb} \%)$ level after completing treatment. Comparable results of Shikha Seth et al reported that $\mathrm{Hb} \%$ raised by $2.8 \mathrm{gm} \%$ at the end of treatment. ${ }^{12}$ In present study percentage of fibroid volume reduction noted was $38.7 \%$, similarly in study conducted by Kulshrestha et al there was $36 \%$ reduction with $25 \mathrm{mg}$ of Mifepristone. Hysterectomy was done in $7 \%$ of patients, in whom heavy menstrual bleeding continued despite of Mifepristone treatment. Shikha Seth et al also reported that $12.1 \%$ of their patients had hysterectomies due to recurrence of symptoms like menorrhagia and 
increase in fibroid volume. Limitations of present study was long term follow up was not done, and endometrial thickness and histology was not studied.

\section{CONCLUSION}

Mifepristone is very useful option in perimenopausal women with symptomatic fibroid and it is also used as preoperative adjunct in patients with severe anemia and large fibroid when surgery is anticipated to be difficult. It reduces fibroid size and its symptoms without any major side effects. However, future long term RCTs are needed to assess the safety and efficacy of Mifepristone.

\section{Funding: No funding sources}

Conflict of interest: None declared

Ethical approval: The study was approved by the Institutional Ethics Committee

\section{REFERENCES}

1. Cramer SF, Patel A. The frequency of uterine leiomyomas. Am J Clinic Pathol. 1990;94(4):435-8.

2. Lurie S, Piper I, Woliovitch I, Glezerman M. Agerelated prevalence of sonographicaly confirmed uterine myomas. J Obstet Gynaecol. 2005;25(1):424.

3. McDonald JW, Rosina A, Rizzi E, Colombo B. Age and fertility: can women wait until their early thirties to try for a first birth?. J Bios Sci. 2011;43(6):685700 .

4. Carlson KJ, Nichols DH, Schiff I. Indications for hysterectomy. New Eng J Med. 1993;328(12):85660 .

5. Maruo $T$, Matsuo $H$, Samoto $T$, Shimomura $Y$, Kurachi O, Gao Z, Wang Y, Spitz IM, Johansson E. Effects of progesterone on uterine leiomyoma growth and apoptosis. Ster. 2000;65(10-11):585-92.
6. Tiltman AJ. The effect of progestins on the mitotic activity of uterine fibromyomas. International journal of gynecological pathology: official journal of the International Soc Gynecol Pathol. 1985;4(2):89-96.

7. Kulshrestha V, Kriplani A, Agarwal N, Sareen N, Garg P, Hari S, Thulkar J. Low dose mifepristone in medical management of uterine leiomyoma-an experience from a tertiary care hospital from north India. Indian J Med Res. 2013;137(6):1154.

8. Higham JM, O'brien PM, Shaw R. Assessment of menstrual blood loss using a pictorial chart. BJOG: Int J Obstet Gynaecol. 1990;97(8):734-9.

9. Narvekar N, Critchley HO, Cheng L, Baird DT. Mifepristone-induced amenorrhoea is associated with an increase in microvessel density and glucocorticoid receptor and a decrease in stromal vascular endothelial growth factor. Human Reproduct. 2006;21(9):2312-8.

10. Murphy AA, Kettel LM, Morales AJ, Roberts VJ, Yen SS. Regression of uterine leiomyomata in response to the antiprogesterone RU 486. The J Clinic Endocrinol Metabol. 1993;76(2):513-7.

11. Angomchanu R, Kapur AN. role of mifepristone in conservative management of fibroids: fc4. 05. Bjog: An International Journal of Obstetrics and Gynaecol. 2014;121:43.

12. Seth S, Goel N, Singh E, Mathur AS, Gupta G. Effect of mifepristone $(25 \mathrm{mg}$ ) in treatment of uterine myoma in perimenopausal woman. J Mid-Life Health. 2013;4(1):22.

Cite this article as: Nachiketha SV, Hadi V. Role of Mifepristone in treatment of uterine fibroid: an experience from tertiary care centre in South India. Int J Reprod Contracept Obstet Gynecol 2019;8:9748 . 